ORIGINAL ARTICLE

\title{
Mould/dampness exposure at home is associated with respiratory disorders in Italian children and adolescents: the SIDRIA-2 Study
}

\author{
M Simoni, E Lombardi, G Berti, F Rusconi, S La Grutta, S Piffer, M G Petronio, C Galassi, \\ F Forastiere, G Viegi, the SIDRIA-2 Collaborative Group
}

Occup Environ Med 2005;62:616-622. doi: 10.1136/oem.2004.018291

See end of article for authors' affiliations

Correspondence to:

Dr G Viegi, Pulmonary

Environmental

Epidemiology Unit, CNR

Institute of Clinical

Physiology, Via Trieste,

41,56126 Pisa, Italy;

viegig@ifc.cnr.it

Accepted 4 March 2005

\begin{abstract}
Aims: To report on the relation between home mould and/or dampness exposure and respiratory disorders in a large sample of children and adolescents in Italy, accounting for age at time of exposure. Methods: 20016 children (mean age 7 years) and 13266 adolescents (mean age 13 years) completed questionnaires on indoor exposures and respiratory symptoms/diseases. Statistical analyses were adjusted for sex, age, questionnaire's compiler, area of residence, season of interview, parental educational status, family history of asthma, rhinitis, eczema, chronic obstructive pulmonary disease, presence of gas water heaters, passive smoking, pets, and active smoking (only for adolescents). Population attributable risk \% (PAR) was also computed.

Results: Asthma was more strongly related to only early than to only current exposure, both in children (OR 1.80, 95\% Cl 1.41 to 2.30) and adolescents (OR 1.89, 95\% Cl 1.38 to 2.59). The same result was found for rhino-conjunctivitis (OR $1.46,95 \% \mathrm{Cl} 1.17$ to 1.82 ), in children, and for wheeze among adolescents (OR 1.56, 95\% $\mathrm{Cl} 1.15$ to 2.11 ). In children, wheeze (OR $1.98,95 \% \mathrm{Cl} 1.47$ to 2.66 ) and eczema (OR $1.44,95 \% \mathrm{Cl} 1.09$ to 1.91 ) were more strongly related to mould/dampness when exposed both early and currently; the same occurred in adolescents for rhino-conjunctivitis $(1.78,95 \% \mathrm{Cl} 1.30$ to 2.45). Although persistent cough/phlegm was significantly related to mould/dampness exposure in children, regardless of exposure timing, no significant association between mould/dampness exposure and eczema or cough/phlegm was found among adolescents. PAR estimates were higher for only early than only current exposures. Avoiding early only exposure would abate wheeze by $6 \%$, asthma or cough/ phlegm by $7 \%$, rhino-conjunctivitis in children by $4 \%$, and in adolescents, asthma by $6 \%$, and wheeze by $4 \%$.

Conclusions: Respiratory disorders such as wheeze and asthma can often be explained by exposure to home mould/dampness, especially early in life. The association seems more evident in children than in adolescents. These findings may suggest the need for environmental prevention strategies.
\end{abstract}

$\mathrm{T}$ e recent increase in allergic and atopic diseases may be the result of complex interactions of environmental and genetic factors. Indeed, there is growing epidemiological evidence that indoor allergen exposure, especially early in life, may contribute to the development of allergic sensitisation. ${ }^{1-3}$ House dust is a common source of indoor allergens. It is a complex mixture of contaminants, such as mites, cat or dog allergens, and moulds. ${ }^{4}$ Little is known about the contribution of indoor mould levels to allergic sensitisation rates. ${ }^{4}$ Although studies that objectively assess exposure would be desirable, there are problems with accurate air sampling. Not all mould components have been identified yet, and there are no methods for a valid quantitative assessment of exposure. ${ }^{5}$ Fewer significant relations of respiratory health outcomes with observed specific mould genera than with reported moulds have been found. ${ }^{6}$ Moreover, a measure of spores cultured using currently available techniques does not accurately represent the variability of concentration over time, because the measurement periods are too short and the variability in repeated measures is increased over a very short period of time.

The important role indoor moulds or dampness play in respiratory functioning has been highlighted. ${ }^{7-10}$ Both selfreported and observed measures of moulds were shown to be associated with increased prevalence of respiratory symptoms and asthma. ${ }^{11}$ Data obtained from a prospective study of adolescents with no history of asthma suggest that a humidifier in the home may contribute to the onset of asthma. ${ }^{12}$ However, the relation between mould/dampness exposure and health outcomes, taking into account age at exposure, has seldom been studied. ${ }^{6}{ }^{13}$

The aim of this paper is to report on the relation between home mould/dampness exposure and respiratory disorders in a large population sample of children and adolescents in Italy, taking into account age of exposure.

\section{METHODS}

In the framework of the ISAAC Project (International Study of Asthma and Allergies in Childhood), ${ }^{14}$ a survey was conducted in Italy between 1994 and 1995 in 10 areas of northern and central Italy in a representative sample of 6-14 year old children/adolescents (1st SIDRIA Study, Studi Italiani sui Disordini Respiratori dell'Infanzia e l'Ambiente). ${ }^{15-17} \mathrm{~A}$ second large, multicentre study on the relation between the environment and respiratory disorders in children and adolescents was carried out in 2002, also including areas of southern Italy (2nd SIDRIA Study). ${ }^{18}$

Abbreviations: $\mathrm{Cl}$, confidence interval; COPD, chronic obstructive pulmonary disease; ISAAC, International Study of Asthma and Allergies in Childhood; OR, odds ratio; PAR, population attributable risk; SIDRIA, Studi Italiani sui Disordini Respiratori dell'Infanzia e l'Ambiente 
This report concerns the 2nd SIDRIA Study, which involved children and adolescents living in five areas of northern Italy (Turin, Milan, Mantua, Trent, and EmiliaRomagna), five areas of central Italy (Rome, Florence, Empoli, Siena, and Colleferro), and two areas of the south (Bari, Palermo). Each area randomly sampled at least 1000 subjects from the local schools, weighted for the total number of students at the school. If the number of subjects to enrol was less than or equal to $25 \%$ of the population, or if there was marked urban or geographic heterogeneity in the area under study, we stratified the population before sampling. Information on children (first and second grade of elementary school) was collected through a questionnaire completed by the parents $(\mathrm{QP}$, children $\mathrm{n}=20016$, schools $\mathrm{n}=235$, response rate $89 \%$ ). Information on adolescents (eighth grade) was collected using two questionnaires, one completed by the parents (QP, adolescents $\mathrm{n}=13616$, schools $\mathrm{n}=166$, response rate $83 \%$ ), and one completed by the adolescents themselves (QA, $\mathrm{n}=16175$, response rate $93 \%$ ). The highest parental response rate was in the north (92\%), followed by the centre $(84 \%)$ and the south $(74 \%)$, while the adolescent response rate was quite similar in the different areas (mean 93\%). For this report, adolescents with both questionnaires were considered $(n=13266,81 \%$ of selected adolescents).

For the timing of mould and/or dampness exposure, valid positive or negative answers to the following questions were considered: "Have you ever seen mould/dampness/fungi on the walls or on the ceiling of your child's bedroom in the first year of your child's life?" (early exposure); "Recently?" (current exposure). With regard to past exposure, the subjects were also allowed to answer "do not remember" (in such case, they were excluded from analyses). The exposure was classified as: only early, when it occurred only in the first year of life; only current, when it occurred only recently; and both, when it occurred in both periods. For both children and adolescents, exposure data were taken from the parental questionnaire. Valid answers about mould/dampness exposure were available for about $90 \%$ of both children and adolescents.

The possible effects of mould/dampness exposure on the following symptoms/diseases were assessed:

(a) Current wheeze: at least one wheezing episode in the previous 12 months.

(b) Current asthma: presence of (1) diagnosis of current asthma made by a physician or hospital admission in the previous 12 months for asthma or current use of medications for asthma AND (2) lifetime asthma or current wheeze or current wheeze after physical exercise or current attacks of dyspnoea with wheeze or current dry cough by night or current chest tightness with wheeze.

(c) Current rhino-conjunctivitis: frequent sneezes or runny/ stuffy nose, apart from common cold/flu with itching/watery eyes, in the previous 12 months.

(d) Eczema: an itchy rash that comes and goes for at least six months, present at any time in the last 12 months, and affecting any of the following places: the folds of the elbows, behind the knees, in front of the ankles, under the buttocks, or around the neck, ears, or eyes OR a skin reddening with itching, at least once in life, in one or more of the following
Table 1 General characteristics of the samples

\begin{tabular}{|c|c|c|}
\hline & Children, $\mathbf{n}(\%)^{*}$ & Adolescents, $\mathbf{n}(\%)^{*}$ \\
\hline \multicolumn{3}{|l|}{ Area } \\
\hline North & $10522(52.6)$ & $5923(44.6)$ \\
\hline Centre & 6536 (32.7) & 5506 (41.5) \\
\hline South & 2958 (14.8) & 1837 (13.8) \\
\hline Total & 20016 & 13266 \\
\hline \multicolumn{3}{|l|}{ Questionnaire's compiler } \\
\hline Mother & $10996(56.1)$ & 7407 (56.9) \\
\hline Father & $915(4.7)$ & $638(4.9)$ \\
\hline Both & $7600(38.8)$ & 4841 (37.2) \\
\hline Other & $97(0.5)$ & $124(1.0)$ \\
\hline \multicolumn{3}{|l|}{ Season } \\
\hline Spring & $4657(23.3)$ & 2902 (21.9) \\
\hline \multicolumn{3}{|l|}{ Mother's education } \\
\hline $0-5$ years & $1223(6.3)$ & 1550 (12.0) \\
\hline 8 years & $6643(34.1)$ & 5004 (38.7) \\
\hline 13 years & $8592(44.1)$ & $4873(37.7)$ \\
\hline University degree & $3043(15.6)$ & 1511 (11.7) \\
\hline \multicolumn{3}{|l|}{ Father's education } \\
\hline $0-5$ years & $1381(7.1)$ & 1535 (12.0) \\
\hline 8 years & 7464 (38.5) & $5276(41.3)$ \\
\hline 13 years & 7425 (38.3) & 4291 (33.6) \\
\hline University degree & 3108 (16.0) & 1660 (13.0) \\
\hline \multicolumn{3}{|l|}{ Mould/dampness } \\
\hline Current & $1703(9.5)$ & $1207(10.1)$ \\
\hline Early & $2290(12.8)$ & $1141(9.5)$ \\
\hline Only current & $985(5.5)$ & $867(7.3)$ \\
\hline Only early & $1572(8.8)$ & $801(6.7)$ \\
\hline Both & $718(4.0)$ & $340(2.8)$ \\
\hline \multicolumn{3}{|l|}{ Passive smoking } \\
\hline At home & $9731(50.2)$ & 6573 (50.9) \\
\hline In the car & - & 3981 (31.8) \\
\hline Current smoking & - & 995 (7.6) \\
\hline \multicolumn{3}{|l|}{ Presence of } \\
\hline Dog & 3444 (17.2) & $3674(27.7)$ \\
\hline Cat & 3484 (17.4) & 3743 (28.2) \\
\hline Gas water heater & 4500 (23.4) & $2874(22.7)$ \\
\hline Current wheeze & $1575(7.9)$ & $1095(8.3)$ \\
\hline Current asthma & $1343(6.7)$ & 863 (6.5) \\
\hline Current rhino-conjunctivitis & $1307(6.5)$ & $2157(16.3)$ \\
\hline Eczema & $1977(9.9)$ & $1031(7.8)$ \\
\hline Persistent cough/phlegm & $575(2.9)$ & $415(3.1)$ \\
\hline
\end{tabular}

sites: elbow folds, back of the knees, ankles, under the gluteus zone, around the neck, around the ears, or around the eyes. ${ }^{19}$

(e) Persistent cough/phlegm: presence of cough and/or phlegm for at least four days a week for at least three months a year apart from common cold/flu.

Except for current asthma (some information used to define current asthma was reported only by parents), we used data from the adolescents for information on their respiratory health.

Information on other indoor factors, such as passive smoking, presence of gas water heater, and presence of dog or cat (anytime throughout life) was also collected. In children, passive smoking exposure was assessed with the question "Are there smokers at home?" Adolescents were considered to be exposed to passive smoking at home if there were smokers at home (from QP) or parents smoked in their presence at home (supplementary information from QA). In adolescents, information on passive smoking exposure from the parents in the car was also available (from QA).

Table 2 Age and sex of samples

\begin{tabular}{|c|c|c|c|c|c|c|c|c|}
\hline Sample (\% males) & $\begin{array}{l}\text { Mean age } \\
\text { (years) }\end{array}$ & SD (range) & $\leqslant 6$ years & $7-8$ years & $\geqslant 9$ years & $\leqslant 13$ years & 14 years & $\geqslant 15$ years \\
\hline $\begin{array}{l}\text { Children (51.4) } \\
\text { Adolescents (51.6) }\end{array}$ & $\begin{array}{r}6.7 \\
13.3\end{array}$ & $\begin{array}{l}0.7(5-11) \\
0.5(12-17)\end{array}$ & $40.5 \%$ & $59.2 \%$ & $0.3 \%$ & $76.3 \%$ & $20.7 \%$ & $2.7 \%$ \\
\hline
\end{tabular}


Statistical analyses were performed using the Statistical Package for the Social Sciences 2000 (SPSS Inc, Chicago, IL, USA): frequency distribution, $\chi^{2}$ test, and logistic regression analysis. The effects of mould/dampness exposure (compared with "never exposure") were assessed by logistic regression analyses. All analyses were adjusted for sex, age, area of residence, questionnaire's compiler, season of interview (possible higher prevalence of allergic symptoms/diseases in spring than in other seasons could influence the reported health outcomes), parental educational status, and active smoking (only for adolescents). Adjustments were also made for other possible indoor risk factors, such as presence of gas appliances (that is, gas water heaters), dogs or cats, passive smoking at home, passive smoking in the car (only for adolescents), and for family history in parents and/or siblings of asthma, rhinitis, eczema, and chronic obstructive pulmonary disease (COPD). Analyses were also accounted for COPD familiarity because family practitioners could perceive chronic persistent asthma as a form of irreversible airflow obstruction, and thus encompass it within the term COPD. In addition, in our experience, even if a relation between familial history for specific respiratory diseases and the presence of specific diseases during life has been observed, the subjects often reported the presence of more than one specific respiratory disease in the family. ${ }^{20}$

Type of heating system and cleaning products was not significantly related with health outcome in bivariate analysis, and they were excluded from further analyses.

Population attributable risk (PAR) was computed to estimate the amount of disease or condition abatable by eliminating the exposure to the specific risk factor:

$\mathrm{PAR}=100 \times \mathrm{p}(\mathrm{RR}-1) / \mathrm{p}(\mathrm{RR}-1)+1$

where $\mathrm{p}=$ proportion of population exposed and $\mathrm{RR}=$ relative risk for exposed versus unexposed.

Approval for this study was obtained from the Bioethics Committee of the Catholic University of Rome.

\section{RESULTS}

The percentage of missing values was less than $10 \%$ for all variables considered. Only the variable season of interview had different amounts of missing values in children and in adolescents: $7 \%$ for adolescents and $0.3 \%$ for children. Other missing values were distributed as following: about $2 \%$ for compiler, $3 \%$ for parental education, $3 \%$ for passive smoking, $6 \%$ for tobacco exposure in car and $1 \%$ for active smoking (adolescents), 4\% for presence of gas water heater, and from $3-10 \%$ for family history.

Tables 1 and 2 show the general characteristics of the samples. Sex was distributed similarly between subjects. Most data originated from northern Italy. Most parental questionnaires were completed by mothers. Parental educational status was higher in children than in adolescents in view of the increasing educational level in Italian younger generations (parents of children are younger than those of adolescents). In general, the prevalence of current mould/ dampness exposure was similar in children and adolescents, whereas early exposure was more frequent in children than in adolescents. Both age groups were frequently exposed to passive smoking.

Current wheeze, current asthma, eczema, and persistent cough/phlegm were quite similarly distributed in the two samples. However prevalence of current rhino-conjunctivitis was higher in adolescents than in children (table 2).

In general, family history of respiratory and atopic disorders was evenly distributed in the two samples. Family history for eczema was more frequent in the mothers than in other first degree relatives.

With regard to the different geographical areas (data not shown), mould/dampness exposure was more frequent in the north/centre than in the south (about $12 \%$ v $7 \%$ for current, $12 \%$ $\checkmark 9 \%$ for early exposure). Parents were less educated in southern Italy. Children/adolescents were more frequently exposed to passive smoking in the centre/south than in the north, whereas the exposure to gas water heaters was higher in the north. Keeping dogs as pets was consistent throughout the country, but cats were more prevalent in the north/centre. In the southern area, $40 \%$ of questionnaires were filled in during the spring ( $20 \%$ in the north/centre). In general, except for eczema in children, the prevalence of symptoms/diseases was higher in the south or the centre than in the north.

\begin{tabular}{|c|c|c|c|c|}
\hline Symptom/disease & Mould/dampness & Prevalence rates \% & $\begin{array}{l}\text { Adjusted* OR } \\
(95 \% \mathrm{CI})\end{array}$ & PAR $\%$ \\
\hline \multirow[t]{4}{*}{ Wheeze } & Never & 6.9 & 1.00 & \\
\hline & Only current & 9.7 & $1.62(1.22-2.15)$ & 3.6 \\
\hline & Only early & 11.6 & $1.65(1.31-2.07)$ & 5.5 \\
\hline & Both & 13.1 & $1.98(1.47-2.66)$ & 3.8 \\
\hline \multirow[t]{4}{*}{ Asthma } & Never & 5.9 & 1.00 & \\
\hline & Only current & 7.2 & $1.39(1.00-1.93)$ & 2.3 \\
\hline & Only early & 10.6 & $1.80(1.41-2.30)$ & 6.7 \\
\hline & Both & 8.9 & $1.17(0.80-1.71)$ & NA \\
\hline \multirow[t]{4}{*}{ Rhino-conjunctivitis } & Never & 6.0 & 1.00 & \\
\hline & Only current & 7.5 & $1.03(0.72-1.49)$ & NA \\
\hline & Only early & 8.1 & $1.46(1.13-1.89)$ & 4.0 \\
\hline & Both & 9.7 & $1.46(1.01-2.09)$ & 1.8 \\
\hline \multirow{4}{*}{ Eczema } & Never & 9.4 & 1.00 & \\
\hline & Only current & 10.9 & $1.17(0.89-1.53)$ & NA \\
\hline & Only early & 12.3 & $1.17(0.94-1.45)$ & NA \\
\hline & Both & 14.9 & $1.44(1.09-1.91)$ & 1.7 \\
\hline \multirow[t]{4}{*}{ Persistent cough/phlegm } & Never & 2.6 & 1.00 & \\
\hline & Only current & 4.0 & $1.86(1.19-2.91)$ & 4.9 \\
\hline & Only early & 3.9 & $1.89(1.31-2.71)$ & 7.4 \\
\hline & Both & 3.8 & $1.64(0.96-2.79)$ & NA \\
\hline
\end{tabular}




\begin{tabular}{|c|c|c|c|c|}
\hline Symptom/disease & Mould/dampness & Prevalence rates \% & Adjusted $^{*}$ OR $(95 \% \mathrm{Cl})$ & PAR $\%$ \\
\hline \multirow[t]{4}{*}{ Wheeze } & Never & 7.7 & 1.00 & \\
\hline & Only current & 10.3 & $1.33(0.98-1.82)$ & NA \\
\hline & Only early & 11.1 & $1.56(1.15-2.11)$ & 3.8 \\
\hline & Both & 10.6 & $1.33(0.84-2.10)$ & NA \\
\hline \multirow[t]{4}{*}{ Asthma } & Never & 5.8 & 1.00 & \\
\hline & Only current & 7.0 & $1.28(0.90-1.82)$ & NA \\
\hline & Only early & 11.4 & $1.89(1.38-2.59)$ & 5.9 \\
\hline & Both & 10.0 & $1.62(1.00-2.62)$ & 1.8 \\
\hline \multirow[t]{4}{*}{ Rhino-conjunctivitis } & Never & 15.7 & 1.00 & \\
\hline & Only current & 17.0 & $1.10(0.86-1.40)$ & NA \\
\hline & Only early & 16.9 & $1.15(0.90-1.47)$ & NA \\
\hline & Both & 23.2 & $1.78(1.30-2.45)$ & 2.3 \\
\hline \multirow[t]{4}{*}{ Eczema } & Never & 7.6 & 1.00 & \\
\hline & Only current & 8.0 & $1.03(0.75-1.42)$ & NA \\
\hline & Only early & 8.0 & $0.76(0.52-1.10)$ & NA \\
\hline & Both & 9.1 & $0.81(0.48-1.35)$ & NA \\
\hline \multirow[t]{4}{*}{ Persistent cough/phlegm } & Never & 3.1 & 1.00 & \\
\hline & Only current & 3.2 & $1.19(0.74-1.91)$ & NA \\
\hline & Only early & 3.6 & $0.80(0.46-1.40)$ & NA \\
\hline & Both & 4.4 & $1.48(0.78-2.81)$ & NA \\
\hline
\end{tabular}

\section{Relation between mould/dampness exposure and health outcomes Children}

In general, prevalence rates of all health outcomes were significantly higher in exposed than in never exposed children (table 3). Except for cough/phlegm, all symptom/ diseases were more prevalent in children exposed only early than in those exposed only currently.

By logistic regression models adjusted for confounding and other risk factors (table 3), asthma (OR 1.80) and rhinoconjunctivitis (OR 1.46) resulted more strongly associated with only early than with only current exposure. Current wheeze and eczema were more strongly related to both early and current exposure than to the variable separately. Persistent cough/phlegm was significantly related to mould/ dampness exposure, regardless of exposure timing. As far as PAR is concerned, about $6 \%$ of wheeze and $7 \%$ of asthma and cough/phlegm resulted attributable to only early exposure.

\section{Adolescents}

Prevalence rates of all health outcomes were significantly higher in exposed than in never exposed subjects. Current asthma figures were similar to those in children. The highest prevalence of asthma was found in subjects exposed to only early mould/dampness, whereas prevalence rates of current wheeze were homogeneous across exposure categories (table 4).

Adjusted odds ratios and adjusted PAR\% are listed in table 4. Current asthma (OR 1.89) and wheeze (OR 1.56) were more strongly related to only early exposure, whereas rhino-conjunctivitis was more strongly related to both exposures (OR 1.78). In adolescents, mould/dampness exposure did not appear to be a significant risk factor for having eczema and persistent cough/phlegm. About $4 \%$ of wheeze and $6 \%$ of asthma were attributable to only early exposure.

\section{DISCUSSION}

We found significant relations between mould/dampness exposure and health outcomes in both children and adolescents. Generally, the association seemed more evident in children than in adolescents, and more evident with early than with current exposure.

The prevalence rate of reported mould/dampness was low (mean $10 \%$ ). In a previous study in the area of the Po river delta (near Venice) we found visible signs of mould in 35\% of dwellings, ${ }^{21}$ but this data concerned mould presence in the kitchen, where other reports have shown that dampness is more likely.22 Reported prevalence rates of home mould/ dampness range widely around the world: from $10-13 \%$ in Russia $^{22}$ and Taiwan, ${ }^{23}$ to $15 \%$ in United Kingdom, ${ }^{24}$ Finland, ${ }^{25}$ and Poland, ${ }^{9}$ to $25 \%$ in the Netherlands, ${ }^{8}$ to $27-28 \%$ in Sweden, ${ }^{26}$ to $38 \%$ in China ${ }^{27}$ and Canada, ${ }^{28}$ and up to $50 \%$ in the USA. ${ }^{8}$ This wide dispersion, despite different climates, might also reflect different methods of data collection. Indeed, we found a significantly lower prevalence of mould/ dampness in southern than in northern/central Italy, probably due to the milder climate of the South. However, it is important to point out that we had only two centres participating from southern Italy.

The association of current wheeze with mould/dampness exposure seemed stronger in children than in adolescents. In the former, the highest OR was found for both exposures. In another study, a stronger association of wheeze with current than with "ever" exposure was found in Russian children exposed to mould. ${ }^{22}$ In adolescents, the strongest risk factor for having wheeze was only early exposure, as also found by other authors. ${ }^{3}$ A significant risk for having wheeze after exposure in the first year of life was also reported by Belanger et al on infants at risk (with an older asthmatic sibling). ${ }^{6}$

The relation between exposure and current asthma was similar for children and adolescents. In our context, only early exposure seems the strongest risk factor for having asthma. This is in agreement with the findings of Forsberg et al, ${ }^{2}$ who reported a more consistent association of asthma with the exposure in the first two years of life than with current exposure.

Rhino-conjunctivitis was positively related to mould/dampness exposure, as shown by others, ${ }^{27}{ }^{29}$ but the results were somewhat different in children and adolescents. In the former, the association was significant with only early but not with only current exposure. Among adolescents, rhino-conjunctivitis was significantly related only to exposure to both. 
Table 5 Estimated odds ratios (OR) and $95 \%$ confidence intervals $(95 \% \mathrm{Cl})$ for the association between mould/dampness current exposure and wheeze/asthma in the literature (questionnaire based studies)

\begin{tabular}{|c|c|c|c|c|c|}
\hline Author (publication year) & n & Age & Design. Definition of mould/dampness exposure & Symptom/disease & OR $(95 \% \mathrm{Cl})$ \\
\hline \multirow[t]{4}{*}{ Present study } & \multirow[t]{2}{*}{17918} & \multirow[t]{2}{*}{7} & \multirow{4}{*}{$\begin{array}{l}\text { Cross sectional. Positive answer to the question: "Have you } \\
\text { seen mould/dampness/fungi on the walls or on the } \\
\text { ceiling of your child's bedroom recently?" }\end{array}$} & Wheeze & $1.78(1.43-2.20)$ \\
\hline & & & & Asthma & $1.29(1.00-1.67)$ \\
\hline & \multirow[t]{2}{*}{11957} & \multirow[t]{2}{*}{13} & & Wheeze & $1.33(1.02-1.74)$ \\
\hline & & & & Asthma & $1.38(1.03-1.85)$ \\
\hline Jedrychowski et al (1998) $)^{9}$ & 1129 & 9 & $\begin{array}{l}\text { Cross sectional. Presence on the walls of any one of: (1) small } \\
\text { moisture stains; (2) larger moisture stains; (3) visible mould on } \\
\text { small surface; (4) visible mould on larger surface }\end{array}$ & Wheeze & $1.63(1.07-2.48)$ \\
\hline Fisher et al $(1998)^{36}$ & 16005 & $7-11$ & $\begin{array}{l}\text { Cross sectional. Presence on the walls of damp spots or mould } \\
\text { during the last two years }\end{array}$ & Wheeze & $\begin{array}{l}1.29(1.06-1.58) \text { to } \\
1.60(1.30-1.97)\end{array}$ \\
\hline Yang et al $(1997)^{23}$ & 4164 & $6-12$ & Cross sectional. Presence of any one of: (1) subjective & Wheeze & $1.81(1.32-2.47)$ \\
\hline & & & $\begin{array}{l}\text { dampness assessment (home was considered damp by the } \\
\text { residents); ( } 2 \text { visible mould or mildew on surfaces inside the } \\
\text { home during the past year; (3) appearance of standing water } \\
\text { within the home/water damage/leaks of water into the building }\end{array}$ & Asthma & $1.73(1.20-2.49)$ \\
\hline Dekker et al $(1991)^{38}$ & 14059 & $5-8$ & $\begin{array}{l}\text { Cross sectional. Presence of any one of: (1) visible mould } \\
\text { growth; (2) wet or damp spots on indoor surfaces; } \\
\text { (3) basement water damage or leaking }\end{array}$ & Wheeze & $1.61(1.39-1.85)$ \\
\hline Dales et al $(1991)^{28}$ & 14948 & $5-8$ & $\begin{array}{l}\text { Cross sectional. Presence of any one of: (1) visible mould } \\
\text { growth; (2) wet or damp spots on indoor surfaces; } \\
\text { (3) basement water damage or leaking }\end{array}$ & Asthma & $1.45(1.23-1.71)$ \\
\hline
\end{tabular}

Eczema was significantly associated with exposure to both among children, in Italy. Similarly, McNally et $a^{30}$ found a significant association between dampness at home and eczema in school aged children in UK (OR 1.50, 95\% CI 1.05 to 2.16 ). The association of cough/phlegm and mould/ dampness was independent from the type of exposure in our children, in agreement with other authors who reported living in homes with presence of mould/dampness as a risk factor for having cough in childhood. ${ }^{23}{ }^{31}$ In our adolescents, the association between exposure and cough/phlegm was not significant. This result might be a result of the confounding effect of other important risk factors for cough/phlegm (that is, active smoking or exposure to passive smoking in the car). Indeed, active smoking was strongly related to cough/phlegm (OR 2.07, 95\% CI 1.43 to 3.00). Also passive smoking in the car (for which information was available on adolescents only) was a significant risk factor for having cough/phlegm (OR $1.63,95 \%$ CI 1.13 to 2.34 ).

According to our PAR estimates, avoidance of any early exposure would decrease wheeze or cough/phlegm by $9 \%$, asthma by $7 \%$, and rhino-conjunctivitis in children by $6 \%$. Similarly, such exposure avoidance would prevent $5 \%$ of wheeze and $8 \%$ of asthma in adolescents. These figures seem relevant in public health terms. PAR estimates regarding only early exposure were lower than the former (tables 3 and 4), but they were higher than those regarding only current exposure. Lee et $a l^{32}$ found very similar PARs for physician diagnosed asthma due to visible mould exposure in Taiwanese schoolchildren: about $6 \%$ for boys and 5\% for girls. Regarding PAR values for other indoor risk factors, an estimated $15 \%$ of asthma and $11 \%$ of wheeze were attributable to passive smoking in our SIDRIA 1st Study, ${ }^{16}$ and in a study from Greenland $47 \%$ of lower respiratory tract infections in children were due to passive smoking. ${ }^{33}$ PAR for asthma was $39 \%$ due to residential dog exposure, environmental tobacco smoke, or gas stove for heating in children in the United States. ${ }^{34}$

We have reported on the possible effects of moulds and/or dampness. From the wording of the questionnaire it is not possible to distinguish mould and dampness. However, a strong association between dampness and mould has been found by other authors, ${ }^{24}{ }^{35}$ thus indicating that dampness in the house could be considered a proxy for the presence of mould. ${ }^{36}$ Moreover, by comparing the health effects of "home dampness" defined either as "presence of moulds" or as "presence of moulds or damp or water damage", it has been shown that exposure definitions did not lead to major changes in the results. ${ }^{25}$

Comparing our results and the findings of other authors is not simple for several reasons. Firstly, we performed a cross sectional study on population samples of children and adolescents, whereas several of the other investigations have concerned case control studies or subjects at high risk for respiratory disorders or symptomatic/ill subjects. ${ }^{16}{ }^{12} 3537 \mathrm{Few}$ studies have regarded adolescents only. ${ }^{12}{ }^{37}$ Moreover, there are few studies on the relation between current symptoms/ diseases and exposure only in the past; in general, the assessments focus on current exposure. Finally, we collected self-reported data on the presence of mould/dampness, whereas in other studies objective inspections or mould exposure quantification were performed or levels of specific moulds were measured. ${ }^{146924}$ Nevertheless, our results confirm the associations of mould/dampness exposure with respiratory symptoms/diseases found by other investigators. $^{78} 101113233839$

However, comparisons between current exposures (independent from the presence/absence of early exposure) may be possible. Table 5 shows odds ratios for the association between current mould/dampness and wheeze or asthma in children or children/adolescents in our study and in other questionnaire based studies. All studies had the same design and similar methods for the exposure definition. Our odds ratios are consistent with those reported by other authors. $^{923} 283638$

Because of some differences in the characteristics and exposures between areas (north, central, and south), we tried to perform geographically stratified analyses. In general, the associations were similar to those found in the whole sample, but only north and central Italy retained significance. This might be due to the amount of data collected in southern Italy (only two centres were represented), the significantly lower prevalence of mould/dampness, or the higher prevalence of other risk factors in this area (that is, passive smoking exposure) which might confound the effects of mould/dampness.

The main limitation of our study is that exposure to mould or dampness was assessed by using questionnaire data. However, questionnaires have been used in many large scale studies, ${ }^{922} 232537$ and their validity has already been established. ${ }^{10} 4041$ 
Overreporting of exposure might result in overestimation of the associations with disorders, but previous studies have found that overreporting seems unlikely to occur, ${ }^{35} 42$ and underreporting exposure is actually more common. ${ }^{43}$ Indeed, we cannot exclude the possibility that the parents of children/ adolescents with diseases (that is, current asthma or rhinoconjunctivitis) tend to remember/report the exposure more often than healthy subjects. However, it was found by other authors ${ }^{24}$ that self-reported questionnaires underestimated the presence of dampness at home when compared with objective inspection and that the tendency to underestimate dampness in the home was independent from the presence/ absence of asthmatic children. Thus, any differential bias of underreporting should have led to conservative results in terms of health outcomes in our study. As a clue of internal validity, it is important to point out that mould/dampness were more prevalent in bedrooms with less exposure to the sun.

In conclusion, exposure to home mould/dampness accounts for a sizeable proportion of respiratory disorders such as wheeze and asthma. The association seems more evident in children than in adolescents, and when the exposure occurs early in life. This finding appears particularly important in view of the increasing trend of allergic sensitisation and atopic diseases worldwide, and given the profound changes that take place in the immune system during its development in infancy. These findings add information on the relations between respiratory health and temporal patterns of mould/dampness exposure, thus suggesting the implementation of environmental preventive strategies.

\section{ACKNOWLEDGEMENTS}

The SIDRIA-2 study has been partially funded by the Italian Ministry of Health.

\section{Authors' affiliations}

M Simoni, G Viegi, Pulmonary Environmental Epidemiology Unit-CNR Institute of Clinical Physiology, Pisa, Italy

E Lombardi, Pediatric Pulmonology Service, "Anna Meyer" Children's University Hospital, Florence, Italy

G Berti, Area di Epidemiologia Ambientale, ARPA Piemonte, Grugliasco, Italy

F Rusconi, Epidemiology Unit, "Anna Meyer" Children's University Hospital, Florence, Italy

S La Grutta, Unità di Allergologia e Pneumologia, Dipartimento di Pediatria, Azienda di Rilievo Nazionale ad Alta Specializzazione (ARNAS), Ospedale Civico and Istituto di Biomedicina e Immunologia Molecolare (IBIM-CNR), Palermo, Italy

S Piffer, Servizio Osservatorio Epidemiologico, Azienda Provinciale per i Servizi Sanitari (APSS), Trento, Italy

M G Petronio, UOS Salute e Ambiente, Empoli, Florence, Italy C Galassi, Servizio di Epidemiologia dei Tumori, AO San Giovanni Battista - CPO Piemonte, Torino, Italy

F Forastiere, Dipartimento di Epidemiologia, ASL Roma E, Rome, Italy

Competing interests: none declared.

The SIDRIA-2 Collaborative Group: Ciccone G and Migliore E (CPO Torino); Mirabelli D, Berti G, and Cadum E (ARPA, Torino); Bugiani M and Piccioni P (CPA, ASL 4, Torino); Bisanti L and Russo A (ASL di Milano); Rusconi F (Anna Meyer Children's University Hospital, Florence) and Bellasio M (Università di Milano); Gianelle V (ARPA, Milano); Piffer S, Battisti L, Kaisermann D, and Gentilini M (APSS di Trento); Giannella G and Talassi F (ASL di Mantova); Caranci N, Frasca G, and Biocca M (ASR, Emilia Romagna); Galassi C (ASR, Emilia Romagna-CPO Piemonte), De Munari E (ARPA, Emilia Romagna); Chellini E (CSPO, Firenze); Lombardi E (Anna Meyer Children's University Hospital, Florence); Biggeri A and Gabellini C (Università di Firenze), Grechi D (ARPAT, Firenze); Petronio MG (ASL di Empoli); Sestini P (Università di Siena); Viegi $G$ and Simoni M (CNR, Pisa); Forastiere F and De Sario M (ASL RM/E, Roma); Pistelli R and Corbo G (Università $S$ Cuore, Roma); Bonci $E$ and Indinnimeo L (Università La Sapienza, Roma); Dell'Orco V (ASL RM/G, Roma); Agabiti N (Agenzia di Sanita' Pubblica del Lazio, Roma); Armenio L, Brunetti L, Cavone M, Lospalluti ML, Massagli M, Polieri G, Rizzi D, Rana FR, and Rana M (Università di Bari); La Grutta S (ARNAS and IBIM-CNR, Palermo).

\section{REFERENCES}

1 Gent JF, Ren P, Belanger K, et al. Levels of household mold associated with respiratory symptoms in the first year of life in a cohort at risk for asthma. Environ Health Perspect 2002;1 10:781-86.

2 Forsberg B, Pekkanen J, Clench-Aas J, et al. Childhood asthma in four regions in Scandinavia: risk factors and avoidance effects. Int J Epidemiol 1997;26:610-19.

3 Lau S, Nickel R, Niggemann B, et al. The development of childhood asthma: lessons from the German Multicentre Allergy Study (MAS). Paediatr Respir Rev 2002;3:265-72.

4 Jacob B, Ritz B, Gehring U, et al. Indoor exposure to molds and allergic sensitization. Environ Health Perspect 2002;110:647-53.

5 Douwes J, Pearce N. Is indoor mold exposure a risk factor for asthma? Am J Epidemiol 2003;158:203-6.

6 Belanger K, Beckett W, Triche E, et al. Symptoms of wheeze and persistent cough in the first year of life: association with indoor allergens, air contaminants, and maternal history of asthma. Am J Epidemiol 2003; 158:195-202

7 Strachan DP. Damp housing and childhood asthma: validation of reporting of symptoms. BMJ 1988;297:1223-6.

8 Brunekreef B, Dockery DW, Speizer FE, et al. Home dampness and respiratory morbidity in children. Am Rev Respir Dis 1989;140:1363-7.

9 Jedrychowski W, Flak E. Separate and combined effects of outdoor and indoor air quality on chronic respiratory symptoms adjusted for allergy among preadolescent children. Int J Occup Med Environ Health 1998;11:19-35.

10 Platt SD, Martin CJ, Lewis CW. Damp housing, mold growth, and symptomatic health state. BMJ 1989;298:1673-8.

11 Billings CG, Howard P. Damp housing and asthma. Monaldi Arch Chest Dis 1998;53:43-9.

12 McDonnell R, Berhane K, Gilliland F, et al. Indoor risk factors for asthma in a prospective study of adolescents. Epidemiology 2002;13:288-95.

13 Dales RE, Miller D, McMullen, eds. Indoor air quality and health: validity and determinants of reported home dampness and moulds. Int J Epidemiol 1997;26:120-5.

14 Asher MI, Keil U, Anderson HR, et al. International Study of Asthma and Allergies in Childhood (ISAAC): rationale and methods. Eur Respir J 1995;8:483-91.

15 Renzoni E, Forastiere F, Biggeri A, et al. Differences in parental- and selfreport of asthma, rhinitis and eczema among Italian adolescents. SIDRIA collaborative Group. Studi Italiani sui Disordini Respiratori dell'Infanzia e I'Ambiente. Eur Respir J 1999;14:597-604.

16 Agabiti N, Mallone S, Forastiere F, et al. The impact of parental smoking on asthma and wheezing. SIDRIA collaborative Group. Studi Italiani sui Disordini Respiratori dell'Infanzia e l'Ambiente. Epidemiology 1999;10:692-8.

17 SIDRIA (Italian Studies on Respiratory Disorders in Childhood and the Environment). Asthma and respiratory symptoms in 6-7 $\mathrm{yr}$ old Italian children: gender, latitude, urbanization and socioeconomic factors. SIDRIA (Italian Studies on Respiratory Disorders in Childhood and the Environment). Eur Respir J 1997;10:1780-6.

18 Galassi C, De Sario M, Biggeri A, et al. Changes in prevalence of asthma and allergies among children and adolescents in Italy, 1994-2002. Pediatrics 2005 (in press).

19 The International Study of Asthma and Allergies in Childhood (ISAAC) Steering Committee. Worldwide variation in prevalence of symptoms of asthma, allergic rhinoconjunctivitis, and atopic eczema: ISAAC. Lancet 1998;351:1225-32.

20 Carrozzi L, Rijcken B, Burney P, et al. Family history for chronic lung diseases and epidemiological determinants of COPD in three European countries. Eur Respir Rev 2001;11:49-54.

21 Simoni M, Biavati P, Carrozzi L, et al. The Po River Delta (North Italy) Indoor Epidemiological Study: home characteristics, indoor pollutants, and subjects' daily activity pattern. Indoor Air 1998;8:70-9.

22 Spengler JD, Jaakkola J, Parise H, et al. Housing characteristics and children's respiratory health. Proceedings Indoor Air 2002;4:461-6.

23 Yang CY, Chiu JF, Kao WY. Damp housing conditions and respiratory symptoms in primary school children. Pedriatr Pulmonol 1997;24:73-7.

24 Williamson IJ, Martin CJ, McGill G, et al. Damp housing and asthma: a casecontrol study. Thorax 1997;52:229-34.

25 Kilpelainen $M$, Terho EO, Helenius $\mathrm{H}$, et al. $\mathrm{M}$. Home dampness, current allergic diseases, and respiratory infections among young adults. Thorax 2001;56:462-7.

26 Engwall K, Norrby C, Norback D. Sick building syndrome in relation to building dampness in multi-family residential buildings in Stockholm. Int Arch Occup Environ Health 2001;74:270-8.

27 Li CS, Hsu LY. Home dampness and childhood respiratory symptoms in a subtropic climate. Arch Environ Health 1996;51:42-6.

28 Dales RE, Zwanenburg $\mathrm{H}$, Burnett $\mathrm{R}$, et al. Respiratory health effects of home dampness and mould among Canadian children. Am J Epidemiol 1991;134:196-203.

29 Zacharasiewicz A, Zidek T, Hidinger G, et al. Symptoms suggestive of atopic rhinitis in children 6-9 years and the indoor environment. Allergy 2000;55:945-50. 
30 McNally NJ, Williams HC, Phillips DR. Atopic eczema and the home environment. Br J Dermatol 2001;145:730-6.

31 Cuijpers CE, Swaen GM, Wesseling G, et al. Adverse effects of the indoor environment on respiratory health in primary school children. Environ Res 1995:68:11-23.

32 Lee YL, Lin YC, Hsive TR, et al. Indoor and outdoor environmental exposures, parental atopy, and physician-diagnosed asthma in Taiwanese schoolchildren. Pediatrics 2003;112:e389.

33 Koch A, Molbak K, Homoe P et al. Risk factors for acute respiratory tract infections in young Greenlandic children. Am J Epidemiol 2003;158:374-84.

34 Lanphear BP, Aligne CA, Auinger $\mathrm{P}$, et al. Residential exposures associated with asthma in US children. Pediatrics 2001;107:505-11.

35 Verhoeff AP, van Strien RT, van Wiinen JH, et al. Damp housing and childhood respiratory symptoms: the role of sensitization to dust mites and molds. Am J Epidemiol 1995;141:103-10.

36 Fisher PH, Kriz B, Martuzzi M, et al. Risk factors and prevalences of childhood respiratory health in four Countries in Western an Central Europe. Indoor Air 1998;8:244-54.
37 Sotir M, Yeatts K, Shy C. Presence of asthma risk factors and environmental exposure related lo upper respiratory infection-triggered wheezing in middle school-age children. Environ Health Perspect 2003;11 1:657-62.

38 Dekker C, Dales R, Bartlett $S$, et al. Childhood asthma and the indoor environment. Chest 1991;100:922-6.

39 Jaakkola JJ, Jaakkola N, Ruotsalainen R. Home dampness and molds as determinants of respiratory symptoms and asthma in pre-school children. $J$ Expo Anal Environ Epidemiol 1993;3(Suppl 1):129-42.

40 Hyndman SJ. Housing dampness and health amongst British Bengalis in east London. Soc Sci Med 1990;30:131-41.

41 Waegemaekers $M$, Van Wageningen N, Brunekreef B, et al. Respiratory symptoms in damp homes. A pilot study. Allergy 1989;44:192-8.

42 Zock JP, Jarvis D, Luczynska C, et al. Housing characteristics, reported mold exposure, and asthma in the European Community Respiratory Health Survey. J Allergy Clin Immunol 2002;1 10:285-92.

43 Norbäck D, Bïornsson E, Janson C, et al. Current asthma and biochemical signs of inflammation in relation to building dampness in dwellings. Int J Tuberc Lung Dis 1999;3:368-376.

\section{bmjupdates+}

bmjupdates+ is a unique and free alerting service, designed to keep you up to date with the medical literature that is truly important to your practice.

bmjupdates+ will alert you to important new research and will provide you with the best new evidence concerning important advances in health care, tailored to your medical interests and time demands.

Where does the information come from?

bmjupdates+ applies an expert critical appraisal filter to over 100 top medical journals A panel of over 2000 physicians find the few 'must read' studies for each area of clinical interest

Sign up to receive your tailored email alerts, searching access and more...

www.bmjupdates.com 